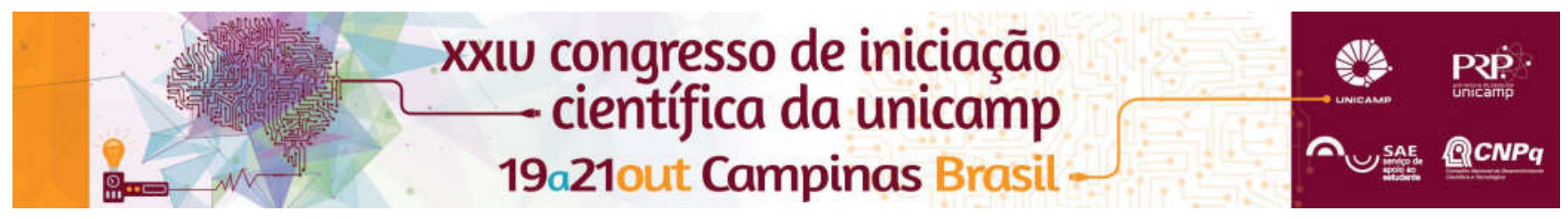

\title{
Influência de epífitas sobre a fauna de Decapoda (Crustacea) associada à alga parda Sargassum sp. em duas praias de Ubatuba, São Paulo, Brasil
}

\author{
Isabella Capistrano C. Soares*, Ana Paula Ferreira, Pedro A. S. Longo, Fosca P. P. Leite
}

\section{Resumo}

A abundancia da fauna associada as macroalgas pode ser influenciada pela biomassa da alga hospedeira e de seus epibiontes. O objetivo do trabalho foi verificar se a biomassa de Sargassum e seus epibiontes influencia a abundancia de decápodes. Para isso foram feitas coletas mensais durante um ano em duas praias da Enseada do Flamengo, Ubatuba-SP. Somente Hyppolyte obliquimanus e Epialtus brasiliensis foram influenciados positivamente pela biomassa dos epibiontes, sendo que o primeiro teve relação negativa com Sargassum. Os demais decapodas não são influenciados pela biomassa de alga.

\section{Palavras-chave: \\ Decapoda, Epifita, Sargassum}

\section{Introdução}

As frondes de Sargassum apresentam alta complexidade estrutural que propicia a ocupação por diferentes grupos de animais. Os crustáceos estão entre os mais representativos em riqueza de espécies e abundância de organismos associados a essa alga parda. A composição e abundancia e distribuição deste grupo de animais podem ser influenciadas pela presença e biomassa de epífitas em relação à biomassa da alga hospedeira. Portanto, o objetivo do trabalho foi verificar se a biomassa de epífitas e de Sargassum sp influencia na abundancia de Decapoda na Praia do Flamengo e de Santa Rita, em Ubatuba

\section{Resultados e Discussão}

A composição da fauna de decápodes associada à Sargassum foi semelhante às de áreas continentais do Estado de São Paulo (Jacobucci et al. 2006). A praia de Santa Rita é menos diversa ( $\left.\mathrm{H}^{\prime}\right)$ do que a praia do Flamengo (Anova, $F=7,856 p=0,00613$ ). Observa-se que na praia Santa Rita, as abundâncias das 5 espécies não estão relacionadas com a abundância das algas hospedeiras. Entretanto, na praia do Flamengo, a abundância do camarão Hippolyte obliquimanus está relacionada positivamente com a biomassa de Sargassum $(F=10,53, p=0,001953)$, e negativamente com a biomassa de epibiontes ( $F=8,541, p=0,004942)$

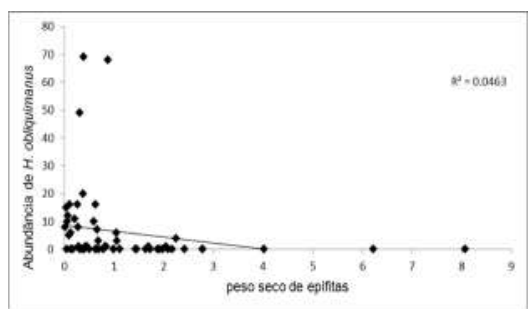

Figura1. Regressão da abundância de Hippolyte obliquimanus e a biomassa de epibiontes

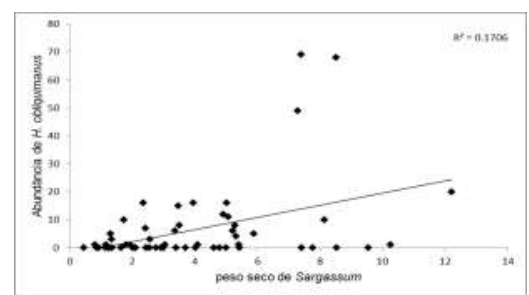

Figura 2. Regressão de abundância de Hippolyte obliquimanus e a biomassa de Sargassum
Também na praia do Flamengo, observa-se um efeito positivo da biomassa de epibiontes sobre a abundância do caranguejo Epialtus brasiliensis $(\mathrm{F}=6,81 \mathrm{p}=0,01145)$.

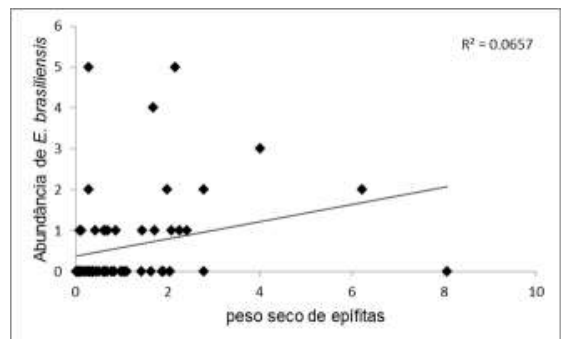

Figura 3. Regressão da abundância de Epialtus brasiliensis e a biomassa de epibiontes.

\section{Conclusão}

O camarão Hippolyte obliquimanus possui como hábito alimentar, principalmente, algas do gênero Sargassum (Duarte, 2011), por isso esta espécie pode estar sendo influenciada positivamente pela biomassa dessa alga. Os epibiontes podem estar relacionados negativamente com a abundância da espécie por provavelmente competirem com Sargassum pela luz e nutrientes. O caranguejo Epialtus brasiliensis tem sua abundância relacionada positivamente com a biomassa de epibiontes, provavelmente devido ao fato de ter como habito a camuflagem com o substrato, fato que pode estar sendo favorecido pelas algas epífitas (Granado, 2014).

\section{Agradecimentos}

A CAPES pelo apoio financeiro concedido. Aos colegas do LICOMAR, principalmente Karine Mansur

\section{Referências bibliográficas}

JACOBUCCI, G. B. \& LEITE, F. P. P. 2006 - Biologia populacional das espécies de Ampithoidae (Crustacea, Amphipoda) associadas a Sargassum filipendula (Phaeophyta, Fucales) na Praia da Fortaleza, Ubatuba, São Paulo, Brasil Revista Brasileira de Zoologia vol.23 no.4 1207-1216

DUARTE, R. C. 2011 Seleção de habitat e natureza polimórfica em populações do camarão Hippolyte obliquimanus Dana,1852 (Decapoda: Caridea) Dissertação apresentada a Faculdade de Filosofia, Ciências e Letras de Ribeirão Preto da USP, como parte das exigências para a obtenção do título de mestre em ciências

GRANADO, P. 2014 Seleção de habitat por Epialtus spp. (Decapoda: Epialtidae) Dissertação apresentada ao Instituto de Biociências da UNESP para obtenção do título de mestre em Zoologia 